\title{
Simvastatin ameliorates injury in an experimental model of lung ischemia-reperfusion
}

\author{
Babu V. Naidu, FRCS \\ Steven M. Woolley, MRCS \\ Alexander S. Farivar, MD \\ Robert Thomas, BA \\ Charles Fraga, MSc \\ Michael S. Mulligan, MD, FACS
}

Objectives: Statins are lipid-lowering drugs with anti-inflammatory and antioxidant properties. This study explores the potential of these commonly prescribed agents to ameliorate lung ischemia-reperfusion injury.

Methods: Left lungs of Long-Evans rats were rendered ischemic for 90 minutes and reperfused for up to 4 hours. Treated animals received simvastatin orally ( 0.5 $\mathrm{mg} / \mathrm{kg}$ ) for 5 days before the experiment. Injury was quantitated in terms of tissue myeloperoxidase content, vascular permeability $\left({ }^{125} \mathrm{I}\right.$ bovine serum albumin extravasation), and bronchoalveolar lavage leukocyte and cytokine content. Changes in nuclear translocation of transcription factors were evaluated by electromobility shift assay. Additional animals received $\mathrm{N}^{\mathrm{G}}$-nitro-L-arginine methyl ester before ischemia-reperfusion to assess whether inhibition of nitric oxide synthase could reverse simvastatin's protective effects. The presence of nicotinamide adenine dinucleotide phosphate oxidase was also evaluated using enzyme staining both histologically and in native electrophoresis.

Results: Lung vascular permeability was reduced in treated animals by $71 \%$ compared with positive controls $(P<.001)$. Administration of $\mathrm{N}^{\mathrm{G}}$-nitro-L-arginine methyl ester reversed this protection. The protective effects of statin pretreatment correlated with a 68\% reduction in tissue myeloperoxidase content $(P<.01)$, marked reductions in bronchoalveolar lavage leukocyte accumulation, and decreased expression of proinflammatory cytokines. Nicotinamide adenine dinucleotide phosphate oxidase expression also decreased with statin treatment.

Conclusion: In addition to its antioxidant properties, the protective effects of simvastatin are likely mediated by modulation of endothelial nitric oxide synthase. The potential to pretreat recipients of lung transplantation with statins to ameliorate reperfusion injury is promising.

sociation, Big Sky, Mont, June 19-22 2002.

Received for publication June 28, 2002; revisions requested Aug 19, 2002; revisions received Dec 13, 2002; accepted for publication Jan 14, 2003.

Address for reprints: Michael S. Mulligan, MD, FACS, Box 356310, University of Washington, 1959 NE Pacific St, Seattle, WA98195(E-mail:msmmd@u.washington. edu).

J Thorac Cardiovasc Surg 2003;126:482-9

Copyright (C) 2003 by The American Association for Thoracic Surgery

$0022-5223 / 2003 \$ 30.00+0$

doi:10.1016/S0022-5223(03)00699-8



tatins are a class of compounds that competitively inhibit the enzyme 3-hydroxy-3-methylglutaryl coenzyme A reductase, the first committed step in cholesterol biosynthesis. Increasingly, the pleiotropic properties of statins are being described. In endothelial cells, all of these effects seem to result from the inhibition of cholesterol's precursor mevalonic acid, which is critical to the isoprenylation of a diverse family of proteins. ${ }^{1}$ Posttranslational prenylation of these proteins is a prerequisite for membrane association and function. Members of this family are involved in cell signaling, differentiation and proliferation, myelination, cellular transport, and cytoskeletal function. ${ }^{2}$

The protective effects of statins have been described in models of renal, cerebral, and cardiac reperfusion injury, ${ }^{3-5}$ as well as in remote lung injury that develops after 
hind-limb ischemia. ${ }^{6}$ In these models, the mechanism mediating this protection is not fully elaborated. Reperfusion is associated with a posttranscriptional reduction in the expression of the enzyme endothelial nitric oxide synthase (eNOS). Preservation of NO production in the reperfusion period seen with statin treatment is believed to protect against postischemic vasoconstriction directly, ${ }^{7}$ and may also do so indirectly by altering endothelin- 1 activity. ${ }^{8}$ Furthermore, NO may inhibit neutrophil-endothelial interactions resulting in reduced neutrophil recruitment and tissue injury. In a model of cerebral reperfusion injury, the protective effects of statin pretreatment were lost in eNOS knockout mice. $^{9}$

After lung transplantation and pulmonary thromboendarterectomy, lung ischemia-reperfusion injury (LIRI) is associated with an increase in vascular permeability and manifests itself clinically as pulmonary edema. ${ }^{10}$ In animal models, this vascular injury is biphasic. ${ }^{11}$ The late phase is dependent on neutrophil recruitment, whereas the early stage is independent of it, occurring within 15 minutes of reperfusion. It is during this early stage that an initial burst of free radical production occurs, believed to be secondary to increased nicotinamide adenine dinucleotide phosphate (NADPH) oxidase activity in alveolar macrophages. Statins have been shown to inhibit NADPH oxidase in vitro resulting in decreased reactive oxygen intermediate (ROI) production. $^{12,13}$

Knowing that statins have anti-inflammatory and antioxidant properties, and are protective in other models of reperfusion injury, we hypothesized that statin pretreatment would be protective against direct LIRI. This protection is likely mediated by modulated expression of NOS and NADPH oxidase.

\section{Materials and Methods \\ Reagents}

All reagents were purchased from Sigma Chemical Company (St Louis, Mo) unless otherwise specified.

\footnotetext{
Animal Model

Pathogen-free adult male Long-Evans rats (Simonsen Labs, Gilroy, Calif), weighing 280 to $320 \mathrm{~g}$, were used for all experiments. All animals received humane care in compliance with the Guidelines for Care and Use of Laboratory Animals, published by the National Society for Medical Research and the National Institutes of Health. An in situ warm ischemia model was used as described previously. ${ }^{14}$ Treated animals received simvastatin $0.5 \mathrm{mg} / \mathrm{kg}$ per day by oral gavage for 5 days before undergoing any experimental procedure. In brief, anesthesia was induced with pentobarbital, and animals were ventilated by tracheostomy (Harvard Rodent Ventilator, Harvard Apparatus Inc, Holliston, Mass). All animals received $0.2 \mathrm{mg}$ of atropine intramuscularly and 50 units of intravenous heparin. Anesthesia was maintained with inhaled halothane. The left lung was mobilized atraumatically through an anterolateral thoracotomy and the left pulmonary artery, veins, and
}

main stem bronchus were occluded with a noncrushing microvascular clamp. At the end of the 90-minute ischemic period, the clamp was removed, and the lung was ventilated and reperfused for periods of up to 4 hours. At the conclusion of the reperfusion period, blood samples were obtained from the inferior vena cava, the heart lung block was rapidly excised, and the pulmonary circulation was flushed with $20 \mathrm{~mL}$ of normal saline solution through the main pulmonary artery.

\section{Lung Permeability Index}

To quantitate lung injury, a permeability index (PI) was determined as described previously. ${ }^{11,14}{ }^{125}$ I-radiolabeled bovine serum albumin (NEN Life Sciences, Boston, Mass), titrated to an activity of 800,000 counts/min per dose, was intravenously injected in a final volume of $1 \mathrm{~mL}$ of $1 \%$ bovine serum albumin phosphatebuffered saline solution 5 minutes before removal of the hilar clamp. At the end of the experiment, the radioactivity counts were quantitated in the left lung and in $1 \mathrm{~mL}$ of inferior vena cava blood using a scintillation counter. The PI was then calculated as follows:

$$
\text { Permeability index }=\frac{\text { Left lung }(\mathrm{cpm})}{1.0 \mathrm{~mL} \text { blood }(\mathrm{cpm})}
$$

This ratio corrected for any variation in systemic blood levels of radioactivity and provided a reproducible measure of lung microvascular permeability.

\section{Treatment with $\mathbf{N}^{\mathbf{G}}$-Nitro-L-Arginine Methyl Ester}

Additional groups of animals underwent pretreatment with an eNOS and inducible NOS (iNOS) inhibitor $\mathrm{N}^{\mathrm{G}}$-nitro-L-arginine methyl ester (L-NAME) before undergoing ischemia-reperfusion as described previously. L-NAME was delivered 30 minutes before ischemia as a $300-\mu \mathrm{L}$ intratracheal injection at a concentration of $5 \mathrm{mmol} / \mathrm{L}$. This dose was used because it was shown to be protective in a rat model of immune complex-induced vasculitis. ${ }^{15}$ Four groups were compared in this experiment, and all underwent ischemia of 90 minutes and reperfusion of 4 hours. The groups consisted of the following: animals receiving L-NAME only, animals receiving statin only, animals not receiving any drugs, and animals receiving statin followed by L-NAME.

\section{Myeloperoxidase Assay}

Tissue myeloperoxidase (MPO) assay content was used to quantitate neutrophil accumulation in the lungs as described previously. ${ }^{14}$ Lung samples were homogenized in a phosphate buffer containing $0.5 \%$ hexadecyltrimethylammonium bromide. Samples were then assayed for the ability to decompose $\mathrm{H}_{2} \mathrm{O}_{2}$ in the presence of O-dianisidine dihydrochloride by the change in absorption at $460 \mathrm{~nm}$ during 1 minute.

\section{Bronchoalveolar Lavage}

Additional animals underwent bronchoalveolar lavage (BAL) at the time of death. Through the tracheostomy, lungs were lavaged individually by clamping the contralateral hilum and instilling 3.0 $\mathrm{mL}$ of saline solution that was flushed and aspirated 3 times. This fluid was centrifuged $\left(1500 \mathrm{~g} \times 8\right.$ minutes at $\left.4^{\circ} \mathrm{C}\right)$ to pellet the cells, and the supernatant was snap-frozen for subsequent cytokine analysis after the addition of a protease cocktail inhibitor (leupep- 


\section{Vascular Permeability}

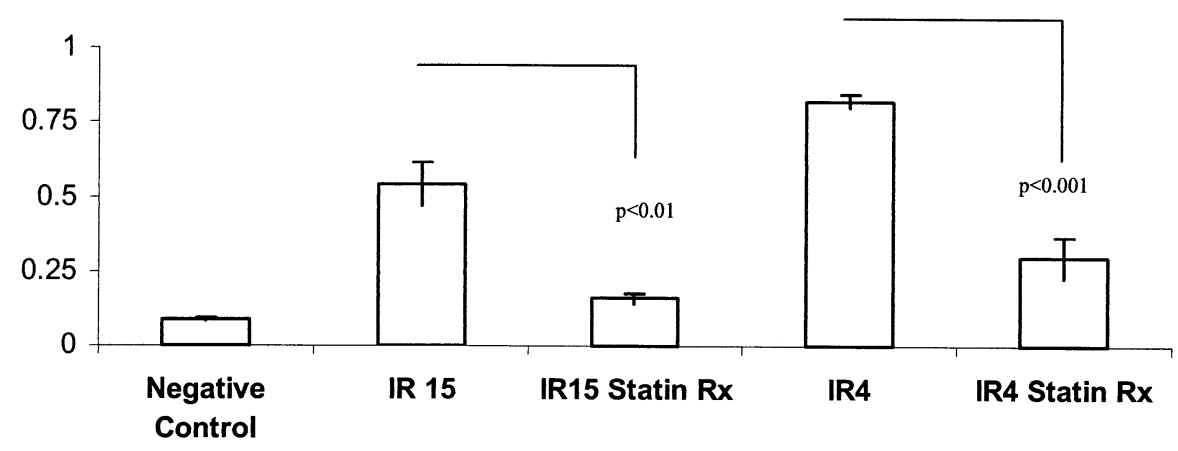

Figure 1. Vascular permeability. Treatment with simvastatin before ischemia-reperfusion showed a significant reduction in vascular permeability at 15 minutes $(P=.01, n=3)$ and 4 hours $(P<.001, n=3)$ of reperfusion.

tin $1 \mu \mathrm{g} / \mathrm{mL}$, aprotinin $1 \mu \mathrm{g} / \mathrm{mL}$, trypsin inhibitor $5 \mu \mathrm{g} / \mathrm{mL}$, and pepstatin A $1 \mu \mathrm{g} / \mathrm{mL}$ ). The red blood cells were lysed, and the pellet was resuspended in normal saline solution. Total nucleated cells were counted using a hemacytometer (Hausser Scientific, Reading, Pa).

\section{Enzyme-Linked Immunosorbent Assay}

A standard sandwich enzyme-linked immunosorbent assay protocol was used to evaluate the elaboration of tumor necrosis factor (TNF)- $\alpha$. The capture antibody was a monoclonal anti-rat TNF- $\alpha$ (R\&D Systems, Minneapolis, Minn) plated at a concentration of $2.5 \mu \mathrm{g} / \mathrm{mL}$. The detection antibody was a biotinylated polyclonal anti-rat TNF- $\alpha$ (R\&D Systems) at $0.25 \mu \mathrm{g} / \mathrm{mL}$. A streptavidin conjugate was used at a 1:1000 dilution (Zymed, San Francisco, Calif), and the detection was quantitated with Sigma Fast ophenylenediamine (OPD).

\section{Electrophoretic Mobility Shift Assay}

Electrophoretic mobility shift assays were performed as previously described ${ }^{14}$ using $32 \mathrm{P}$ end-labeled oligonucleotides specific for the consensus binding sequence of nuclear factor- $\kappa \mathrm{B}(\mathrm{NF}-\kappa \mathrm{B})$ and activator protein-1 (AP-1; Promega, Madison, Wis).

\section{Western Blot Analysis for eNOS and iNOS}

Antibodies for eNOS and iNOS (Signal Transduction Laboratories, Lexington, Ky) were used at 1:500 dilutions. Expression of eNOS and iNOS in cytosolic protein samples was assessed by Western blot analysis. Membranes were developed using standard horseradish peroxidase and avidin biotin complex methods.

\section{Enzymatic Localization and Characterization of NADPH Oxidase}

NADPH diaphorase is a histochemical $\operatorname{stain}^{14}$ that uses exogenous-reduced NADPH as a substrate and the chromophore nitroblue tetrazolium as a redox indicator. Frozen sections of optimal cutting temperature-filled lungs were incubated with a Tris $\mathrm{HCl}$ buffer containing nitroblue tetrazolium $(1 \mathrm{mg} / \mathrm{mL})$ and $\beta$-NADPH $(0.4 \mathrm{mg} / \mathrm{mL})$ in a humidified chamber for 1 hour at $37^{\circ} \mathrm{C}$. Sections were dehydrated, mounted, and examined by light microscopy.

\section{Enzyme Electrophoresis}

Nondenaturing $6.0 \%$ polyacrylamide gels were cast containing 1.5 $\mathrm{mmol} / \mathrm{L}$ Tris, $\mathrm{pH} 8.8$, acrylamide, TEMED, and ammonium persulfate. The separating gel was overlaid with water-saturated butanol and allowed to polymerize for 1 hour. A 4\% stacking gel was cast containing $0.5 \mathrm{mmol} / \mathrm{L}$ Tris $\mathrm{pH} 6.8$, acrylamide, TEMED, and ammonium persulfate. Samples were mixed with native sample buffer consisting of $62.5 \mathrm{mmol} / \mathrm{L}$ Tris, $\mathrm{pH} 6.8,40 \%$ glycerol, $0.01 \%$ xylene cyanol $\mathrm{FF}$, and $0.01 \%$ bromophenol blue at a ratio of 1:2. Bio-Rad Laboratories (Hercules, Calif) prestained standards were loaded ( $5 \mu \mathrm{L})$, as was $20 \mu \mathrm{g}$ of cytoplasmic protein. The gels were then electrophoresed for 4 to 6 hours at $4^{\circ} \mathrm{C}$.

\section{Enzyme Staining of Polyacrylamide Gels}

The gel was equilibrated in a Tris- $\mathrm{HCl}$ buffer $\mathrm{pH} 7.4$ (3.25 g Tris, $1.65 \mathrm{~mL}$ concentrated $\mathrm{HCl}$ acid, and the volume raised to $500 \mathrm{~mL}$ with distilled water). The gel was then placed in a shallow dish containing $20 \mathrm{~mL}$ of staining solution (Tris- $\mathrm{HCl}$ buffer, $20 \mathrm{mg}$ nitro blue tetrazolium salt, and $8 \mathrm{mg} \beta$-NADPH). The gel was incubated for 1 to 2 hours at $37^{\circ} \mathrm{C}$ with periodic agitation.

\section{Statistical Analysis}

All data are presented as mean \pm SE of the mean. Data sets were analyzed using Microsoft Excel 97 (Microsoft Corp, Redmond, Wash) and SPSS version 10 (SPSS Inc, Chicago, Ill). Comparisons between control groups or between positive controls and treated animals were performed by the Student $t$ test. Analyses between more than 2 groups were performed with analysis of variance with control for multiple comparisons.

\section{Results}

Statin Pretreatment Reduces Vascular Permeability

Vascular permeability was assessed at 15 minutes and 4 hours of reperfusion. At 15 minutes of reperfusion, injured lungs demonstrated an increase in the PI to $0.54 \pm 0.07$. This was reduced by $84.5 \%(0.16 \pm 0.02)(P<.008, \mathrm{n}=$ 4 ) after pretreatment with simvastatin for 5 days (Figure 1). 
A

Tissue Neutrophil Sequestration

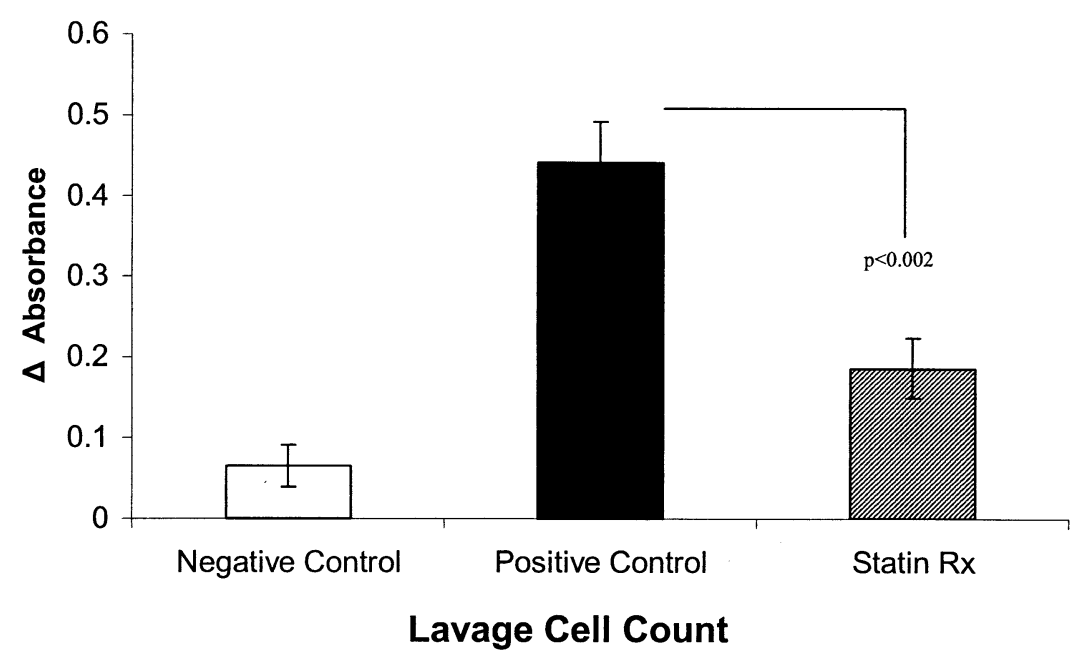

B

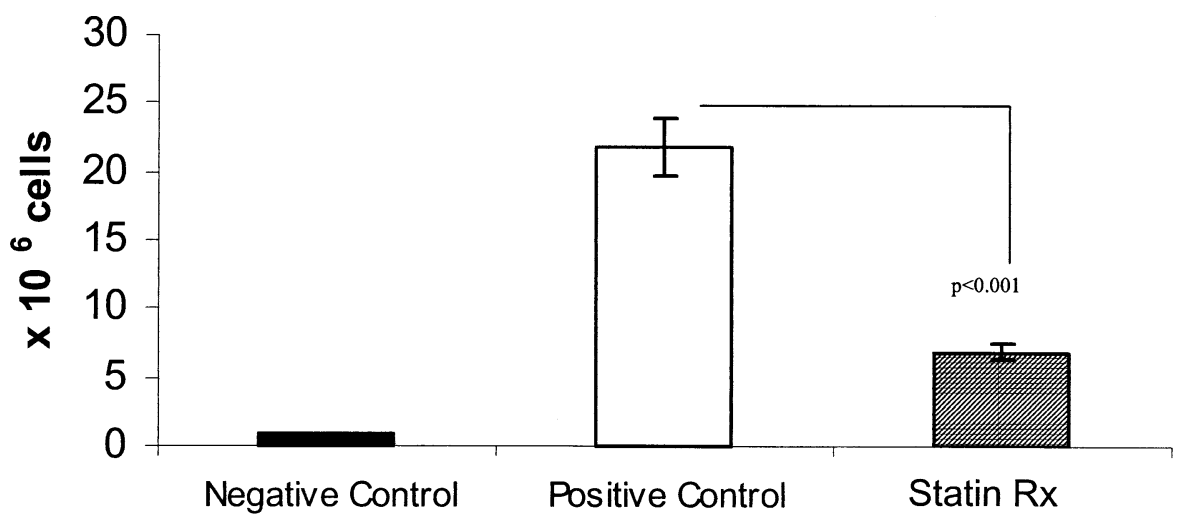

Figure 2. Neutrophil recruitment. A, Tissue neutrophil accumulation as measured by myeloperoxidase (MPO) content was statistically increased at 4 hours of reperfusion when compared with negative controls $(P<.001)$. These values were markedly decreased in statin-treated animals $(P<.002, n=4)$. B, The bronchoalveolar lavage (BAL) cell counts increased 26 -fold in animals undergoing ischemia-reperfusion when compared with negative controls $(P<.001)$. A significant decrease in leukocyte accumulation was noted in BAL from animals receiving statin $(P<.001, \mathrm{n}=4)$.

At 4 hours of reperfusion, the PI increased from $0.09 \pm$ 0.01 to $0.82 \pm 0.022$ with injury $(P<.001)$. Statin pretreatment reduced lung vascular permeability by $71 \%(P<$ $.001, \mathrm{n}=3$ ) (Figure 1).

\section{Effect of Statin Pretreatment on Neutrophil}

Recruitment

Tissue MPO content increased by 10.7 -fold $(0.041 \pm 0.01$ $0.44 \pm 0.005, P<.01)$ and BAL cell count increased by 26 -fold $\left(0.8 \pm 0.2-21.8 \pm 2.1 \times 10^{6}\right.$ cells, $\left.P<.001\right)$ in lungs subjected to 90 minutes of ischemia followed by 4 hours of reperfusion. There was a 64\% $(0.19 \pm 0.04, P<$ $.002, \mathrm{n}=4$ ) (Figure 2, $A$ ) reduction in tissue MPO content and a $71 \%$ reduction $\left(6.85 \pm 0.56 \times 10^{6}\right.$ cells $P<.001, \mathrm{n}$ $=4)$ (Figure 2, $B$ ) in leukocyte accumulation in the alveolar space in statin-treated animals.

\section{Effect of Treatment with L-NAME}

Permeability indices at 4 hours of reperfusion were compared in animals treated with statin and in animals treated with statin and L-NAME. L-NAME treatment alone resulted in a PI similar to that of untreated animals subjected to ischemia and 4 hours of reperfusion $(0.71 \pm 0.18$ vs $0.75 \pm$ $0.08 P=\mathrm{NS})$. Although statin pretreatment produced a marked decrease in vascular permeability, this was reversed with administration of L-NAME $(\mathrm{n}=3)$ (Figure 3$)$. 


\section{Vascular Permeability}

(L-NAME Treatment)

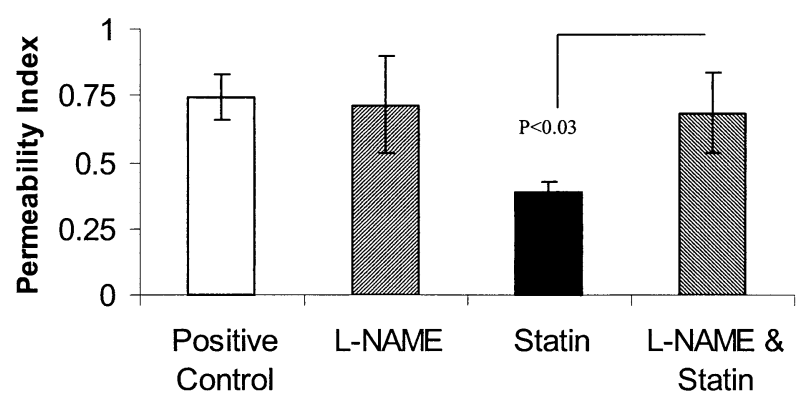

Figure 3. Reversal of statin protection with $\boldsymbol{N}^{\boldsymbol{G}}$-nitro-L-arginine methyl ester (L-NAME). There was no significant difference in lung vascular permeability between untreated animals and animals treated with L-NAME after 4 hours of reperfusion. The decrease in permeability associated with statin treatment was reversed with concurrent L-NAME administration $(P<.03)$.

\section{Reduced Cytokine Content in BAL Associated With Statin Pretreatment}

Three groups were studied: unmanipulated negative controls, positive controls that underwent 90 minutes of ischemia followed by 4 hours of reperfusion, and statin-pretreated animals subjected to the same LIRI protocol. TNF- $\alpha$ secretion in the BAL increased from $51 \pm 2.4 \mathrm{pg} / \mathrm{mL}$ in the negative controls to $658 \pm 63 \mathrm{pg} / \mathrm{mL}$ in the positive controls $(P<.004)$. This was reduced with statin pretreatment by $52 \%$ to $344 \pm 43 \mathrm{pg} / \mathrm{mL}(P=.013, \mathrm{n}=4)$ (Figure 4$)$.

\section{Transcription Factor Modulation by Statin Pretreatment}

To determine additional mechanisms mediating statin's protection in LIRI, the expression of 2 proinflammatory nuclear transcription factors were studied. Shown in Figure 5 are representative electrophoretic mobility shift assays detailing the nuclear translocation of NF- $\kappa \mathrm{B}$ and AP-1 in controls and injured left lungs. There is minimal nuclear NF- $\kappa \mathrm{B}$ and AP-1 detected in negative control animals, whereas significant translocation of both is apparent in the animals that underwent ischemia and 15 minutes of reperfusion. The bands that were representative for both NF- $\kappa \mathrm{B}$ and AP-1 were specified using cold competition with nonlabeled oligonucleotide (not shown). Statin-pretreated animals clearly demonstrate decreased translocation of NF- $\kappa \mathrm{B}$ to the nucleus at 15 minutes of reperfusion $(n=4)$.

\section{Effect of Statin Treatment on eNOS and iNOS}

The expression of eNOS protein was studied by Western blot in negative controls, positive controls, and injured animals pretreated with statin. Samples from positive controls and statin-treated groups were obtained after $90 \mathrm{~min}$ - utes of ischemia and 15 minutes or 4 hours of reperfusion. Representative membranes are illustrated in Figure 6. Unmanipulated nontreated and statin-treated animals both demonstrated modest eNOS expression. After ischemia and 15 minutes of reperfusion, there was an increase in eNOS expression in both groups. Although eNOS expression is reduced at 4 hours of reperfusion in positive controls, statintreated animals demonstrated preserved and even increased expression of eNOS protein $(\mathrm{n}=4)$. Additional Western blots for iNOS demonstrated that ischemia-reperfusion did not alter baseline expression (data not shown). This was true in both control and statin-treated groups.

\section{Effect of Statin Pretreatment on NADPH Oxidase Activity}

In addition to modulating eNOS activity, another potential mechanism of protection of statins in reperfusion injury is believed to be the inhibition of NADPH oxidase expression, which would reduce the generation of free radicals. We therefore assayed for enzyme oxidases in frozen sections of injured lungs exposed to 90 minutes of ischemia followed by 15 minutes of reperfusion. There is a marked increase in staining in injured lungs (Figure 7, $B$ ) when compared with unmanipulated negative controls (Figure 7, A). However, in statin-treated animals there is a marked reduction in staining (Figure 7, C). Enzyme electrophoresis performed for NADPH oxidase showed marked expression at 15 minutes of reperfusion. This band disappears completely in statinpretreated animals undergoing reperfusion of 15 minutes (Figure 8). This indicates that the reduction in positive staining seen in the histochemistry is probably caused by early inhibition of NADPH oxidase associated with statin pretreatment.

\section{Discussion}

The pleiotropic effects of statins seem to result from the inhibition of cholesterol's precursor mevalonic acid, which is critical to the isoprenylation of diverse group of proteins. ${ }^{17}$ Two functionally distinct pathways of prenylation covalently attach a lipid (geranylgeranyl or farnesyl) to different groups of membrane-associated proteins, allowing their localization to discrete subcellular locations. Examples of this are the Ras and Rho guanosine triphosphate (GTP)binding proteins. In endothelial cells, Ras translocation is dependent on farnesylation, whereas Rho requires geranylgeranylation. ${ }^{18}$ The active forms (GTP-Rho/Ras) interact with specific kinases to activate downstream targets. Statins inhibit both types of prenylation, leading to the inactivation of Rho and Ras in the cytoplasm. The inactive cytosolic forms (guanosine diphosphate-Rho/Ras) cycle with the active membrane bound GTP-Rho/Ras.

In vitro studies of reperfusion injury indicate that the increase in eNOS expression seen with statin pretreatment is reversed by the addition of farnesyl but not geranyl donors. 


\section{TNF $\alpha$}

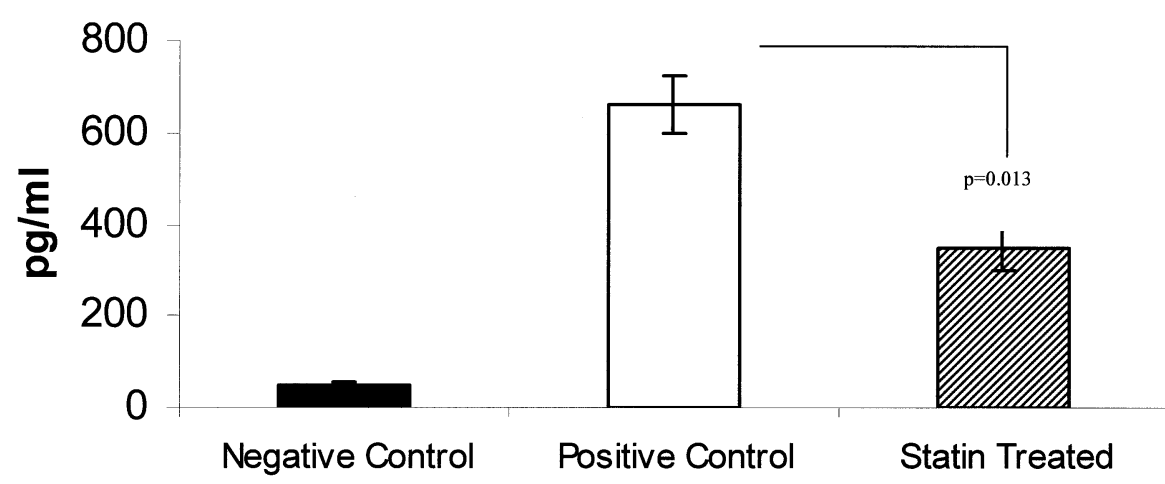

Figure 4. Enzyme-linked immunosorbent assay for tumor necrosis factor (TNF)- $\alpha$ content of lavage fluid. There was a marked increase in TNF- $\alpha$ content in lavage fluid from left lungs at 4 hours of reperfusion. Statin-treated animals demonstrated a significant reduction of TNF- $\alpha$ when compared with positive controls $(P<.013 ; n=4)$.

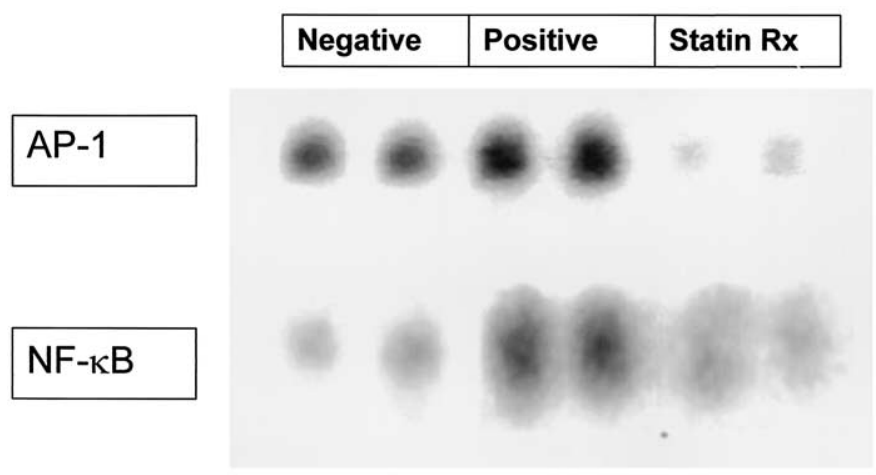

Figure 5. Electrophoretic mobility shift assay for nuclear factor (NF)-кB and activator protein (AP)-1. The first 2 columns represent unmanipulated negative controls. The middle 2 columns are positive controls subjected to ischemia and 15 minutes of reperfusion. The final 2 columns reveal a marked reduction in nuclear translocation of NF- $\kappa$ B and AP-1 in animals treated with simvastatin $(n=4)$.

\begin{tabular}{|c|c|c|c|c|}
\hline Normal & IR 15 Min & $\begin{array}{c}\text { IR 15 Min } \\
\text { Treated }\end{array}$ & IR 4 hrs & $\begin{array}{c}\text { IR 4 hrs } \\
\text { Treated }\end{array}$ \\
\hline \hline & & & & \\
\hline
\end{tabular}

Figure 6. Western blot for endothelial nitric oxide synthase (eNOS) expression. eNOS protein, with ischemia and 15 minutes of reperfusion, is increased above baseline in both treated and nontreated groups. Conversely, eNOS expression persists only in the statin-treated group at 4 hours of reperfusion.

Although such reversal is not pharmacologically possible in vivo, Rho inhibition of Clostridium botulinum C3 transferase promotes eNOS up-regulation in endothelial cells. ${ }^{19}$ Therefore, statin-induced up-regulation of eNOS expression is believed to occur by an inhibition of the Rho GTPase protein. The observed pattern of eNOS up-regulation with hypoxia and gradual diminution with ensuing reperfusion is in agreement with other in vivo studies. ${ }^{4,7,9}$ Blockade of eNOS was shown to worsen late, but not early, reperfusion injury, indicating that eNOS activity is protective against late reperfusion injury. Therefore, in the present study, the persistence of eNOS protein at 4 hours of reperfusion in statin-treated animals likely explains the reduction in late tissue injury and neutrophil accumulation. This hypothesis 



Figure 7. Nicotinamide adenine dinucleotide phosphate (NADPH) diaphorase stain. Statin treatment reduces NADPH-dependent oxidase activity in left lungs at 15 minutes of reperfusion when compared with nontreated controls. Frozen sections stained are as follows. A, Normal left lung $(\times 200)$. B, Nontreated left lungs subjected to ischemia and 15 minutes of reperfusion $(\times 200)$. C, Simvastatin pretreatment followed by ischemia and 15 minutes of reperfusion $(\times 200)$.

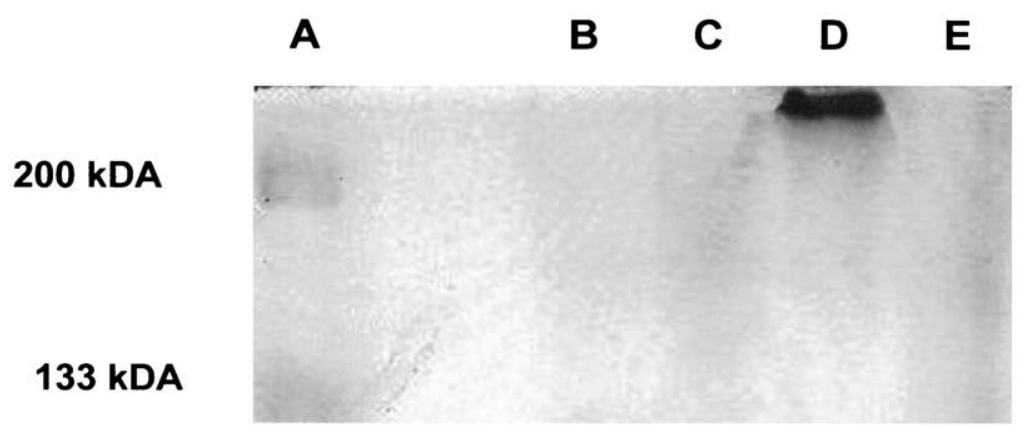

Figure 8. Characterization of NADPH oxidase activity. Nondenaturing electrophoresis of whole lung protein lysates were performed on $6 \%$ polyacrylamide gels. Gels were stained for enzyme activity using a modified diaphorase. A, Prestained standard. Myosin (200 kDa) and $\beta$-galactosidase (133 kDa). B, Unmanipulated lungs. C, Lungs from statin-treated unmanipulated animals. D, Animals subjected to ischemia and 15 minutes of reperfusion. Contains a single band (calculated molecular weight $253 \mathrm{kDa}$ ) that correlates to intact NADPH oxidase (molecular weight $267 \mathrm{kDa}$ ). E, Statin-treated animals subjected to ischemia and 15 minutes of reperfusion. Statin pretreatment resulted in a dramatic reduction in NADPH oxidase activity.

is supported by the fact that the protective effects of statins in late (4 hours) reperfusion are reversed by the administration of the eNOS and iNOS antagonist L-NAME.

Another potential mechanism mediating the protective effects of statins may involve inhibition of free radical production. ${ }^{20-22}$ In vitro, the reduction in production of ROIs seen after statin treatment is associated with inhibition of NAPDH oxidase activity in macrophages ${ }^{12}$ and endothelial cells. ${ }^{13}$ In this study, we demonstrated that after treatment with statins, the expression of NADPH oxidase is inhibited, which would result in a decrease in mitochondrial ROI production. Not only do ROIs have direct toxic effects, they also stimulate the transcription factors NF- $\kappa \mathrm{B}$ and AP- $1 .{ }^{23}$ These transcription factors, once activated, promote the transcription of a number of cytokines, chemokines, and adhesion molecules that potentiate tissue injury by neutrophil recruitment and endothelial damage. ${ }^{24}$ Therefore, statin inhibition of free-radical production has widespread effects on the proinflammatory cascade.

In the field of lung transplantation, the ability to pretreat donors or recipients with a currently used, readily available drug makes the potential use of statins very promising. Further studies using an orthotopic transplant model will likely delineate other potential benefits from their administration to either the donor or recipient. Furthermore, the availability of parenteral formulations of statins (which could be added to lung preservative solutions) may allow for the development of novel protective strategies. 


\section{Summary}

This study has shown that pretreatment with simvastatin is protective against lung reperfusion injury in a rodent model. The likely mechanisms of protection include altered free radical generation through effects on NADPH oxidase and preservation of endogenous NO activity.

\section{References}

1. Goldstein JL, Brown MS. Regulation of the mevalonate pathway. Nature. 1990;343:425-30.

2. Corsini A, Bellosta S, Baetta R, Fumagalli R, Paoletti R, Bernini F. New insights into the pharmacodynamic and pharmacokinetic properties of statins. Pharmacol Ther. 1999;84:413-28.

3. Joyce M, Kelly C, Winter D, Chen G, Leahy A, Bouchier-Hayes D. Pravastatin, a 3-hydroxy-3-methylglutaryl coenzyme A reductase inhibitor, attenuates renal injury in an experimental model of ischemiareperfusion. J Surg Res. 2001;101:79-84.

4. Lefer AM, Campbell B, Shin YK, Scalia R, Hayward R, Lefer DJ. Simvastatin preserves the ischemic-reperfused myocardium in normocholesterolemic rat hearts. Circulation. 1999;100:178-84.

5. Samdani AF, Dawson TM, Dawson VL. Nitric oxide synthase in models of focal ischemia. Stroke. 1997;28:1283-8.

6. Joyce M, Kelly CJ, Chen G, Bouchier-Hayes DJ. Pravastatin attenuates lower torso ischaemia-reperfusion-induced lung injury by upregulating constitutive endothelial nitric oxide synthase. Eur J Vasc Endovasc Surg. 2001;21:295-300.

7. Laufs U, Fata VL, Liao JK. Inhibition of 3-hydroxy-3-methylglutaryl (HMG)-CoA reductase blocks hypoxia-mediated down-regulation of endothelial nitric oxide synthase. J Biol Chem. 1997;272:31725-9.

8. Sakurai T, Yanagisawa M, Masaki T. Molecular characterization of endothelin receptors [review]. Trends Pharmacol Sci. 1992;13:103-8.

9. Endres M, Laufs U, Huang Z, Nakamura T, Huang P, Moskowitz MA, et al. Stroke protection by 3-hydroxy-3-methylglutaryl (HMG)-CoA reductase inhibitors mediated by endothelial nitric oxide synthase. Proc Natl Acad Sci U S A. 1998;95:8880-5.

10. Meyers BF, Lynch J, Trulock EP, Guthrie TJ, Cooper JD, Patterson GA. Lung transplantation: a decade of experience. Ann Surg. 1999; 230:362-70.

11. Eppinger MJ, Jones ML, Deeb M, et al. Pattern of injury and the role of neutrophils in reperfusion injury of rat lung. J Surg Res. 1995;58: 713-18.

12. Giroux LM, Davignon J, Naruszewicz M. Simvastatin inhibits the oxidation of low-density lipoproteins by activated human monocytederived macrophages. Biochim Biophys Acta. 1993;1165:335-8.

13. Wagner AH, Kohler T, Ruckschloss U, Just I, Hecker M. Improvement of nitric oxide-dependent vasodilatation by HMG-CoA reductase inhibitors through attenuation of endothelial superoxide anion formation. Arterioscler Thromb Vasc Biol. 2000;20:61-9.

14. Krishnadasan B, Naidu B, Rosengart M, Farr AL, Barnes A, Verrier $\mathrm{ED}$, et al. Decreased lung ischemia-reperfusion injury in rats after preoperative administration of cyclosporine and tacrolimus. $J$ Thorac Cardiovasc Surg. 2002;123:756-67.

15. Mulligan MS, Moncada S, Ward PA. Protective effects of inhibitors of nitric oxide synthase in immune complex-induced vasculitis. $\mathrm{Br} \mathrm{J}$ Pharmacol. 1992;107:1159-62.

16. Ross MH, Reith EJ, Romrell LJ. Histology text and atlas. 2nd ed. Baltimore (MD): Williams \& Wilkins; 1989.

17. Goldstein JL, Brown MS. Regulation of the mevalonate pathway. Nature. 1990;343:425-30.

18. Laufs U, Liao JK. Direct vascular effects of HMG-CoA reductase inhibitors. Trends Cardiovasc Med. 2000;10:143-8.

19. Aktories K. Bacterial toxins that target Rho proteins. J Clin Invest. 1997;99:827-9.

20. Obata T, Ebihara A, Yamanaka Y. Effect of fluvastatin, an inhibitor of 3-hydroxy-3-methylglutaryl coenzyme A reductase, on nitric oxideinduced hydroxyl radical generation in the rat heart. Biochim Biophys Acta. 2001;1536:55-63.

21. Takemoto M, Node K, Nakagami H, Liao Y, Grimm M, Takemoto Y, et al. Statins as antioxidant therapy for preventing cardiac myocyte hypertrophy. J Clin Invest. 2001;108:1429-37.

22. Yamamoto A, Hoshi K, Ichihara K. Fluvastatin, an inhibitor of 3-hydroxy-3-methylglutaryl-CoA reductase, scavenges free radicals and inhibits lipid peroxidation in rat liver microsomes. Eur J Pharmacol. 1998;361:143-9.

23. Chandel NS, Maltepe E, Goldwasser E, Mathieu CE, Simon MC, Schumacker PT. Mitochondrial reactive oxygen species trigger hypoxia-induced transcription. Proc Natl Acad Sci U S A. 1998;95: 11715-20.

24. Baldwin AS Jr. The NF-kappa B and I kappa B proteins discoveries and strategies. Аnnu Rev Immunol. 1996;14:649-81. 